năng tâm trương trên nhóm bệnh nhân đái tháo đường.

\section{KẾT LUẬN}

- Tỷ lệ sóng TाT thất trái là $90 \%$ ở nhóm ĐTÐ, 93,3\% ở nhóm chứng nhưng sự khác biệt chưa có ý nghĩa thống kê $(p>0,05)$.

- Vận tốc STTT thất trái ở nhóm bệnh nhân ĐTÐ typ 2 là $64.7 \pm 15.5 \mathrm{~cm} / \mathrm{s}$, lớn hớn so với vận tốc STTT thất trái ở nhóm chứng khỏe mạnh $(56.2 \pm 11.3 \mathrm{~cm} / \mathrm{s})(\mathrm{p}<0.05)$.

- Vận tốc STTT ở nhóm ĐTĐ có rối loạn CNTTr cao hơn nhóm ĐTĐ không có rối loạn $\operatorname{CNTTr}(74,3 \pm 11,3$ so với $58,5 \pm 11,2, \mathrm{p}<0,001)$.

\section{TÀI LIÊU THAM KHẢO}

1. Trân Hữu Dàng, Thái Hồng Quang, \& Nguyễn Hải Thủy và CS. Bệnh lý tim mạch và các khuyến cáo điều trị các nguy cơ tim mạch ở bệnh nhân đái tháo đường. Hội Nội Tiết Và Đái Tháo Đường Việt Nam (2018).

2. Patil, V. C., Patil, H. V., Shah, K. B., Vasani, J. D. \& Shetty, P. Diastolic dysfunction in asymptomatic type 2 diabetes mellitus with normal systolic function. J. Cardiovasc. Dis. Res.2, 213222 (2011).

3. Kul, S. et al. Presystolic Wave is Associated with Subclinical Left Ventricular Dysfunction Assessed by Myocardial Performance Index in Type 2 Diabetes Mellitus. Arq. Bras. Cardiol. (2019) doi:10.5935/abc.20190134.

4. American Diabetes Association. Classification and Diagnosis of Diabetes ADA 2019. Diabetes Care42, S13-S28 (2019).

5. Özmen C, Kaya B, Eker Akıllı R, et al. The presystolic wave was not sufficient for diagnosing subclinical left ventricular diastolic dysfunction in hemodialysis patients. Cukurova Med J. 2019;44:529-538. doi:10.17826/cumj.623583

6. Mittal SR, Pancholi N. Left ventricular outflow tract presystolic flow velocity - another marker of left ventricular diastolic function. Published online 2001:8-13

7. Joshi KR, Kabirdas D, Romero-Corral A, Shah M, Figueredo VM, Pressman GS. Clinical Significance of a Presystolic Wave on Doppler Examination of the Left Ventricular Outflow Tract. Am J Cardiol. 2014;114(10):1599-1602. doi:10.1016/j.amjcard.2014.08.048.

\title{
KẾT QUẢ HÓA XẠ TRI (IMRT) ĐỒNG THỜI UNG THƯ THANH QUẢN GIAI ĐOẠN III - IV TẠI BỆNH VIỆN K
}

\section{TÓM TẮT}

Mục tiêu: Nhận xét một số đặc điểm lâm sàng, cận lâm sàng và đánh giá kểt quả hóa xạ trị đồng thời bệnh nhân ung thư thanh quản giai đoạn III-IV tại BV $\mathrm{K}$ giai đoạn 2018 - 2021. Đối tượng và phương pháp nghiên cứu: Nghiên cứu mô tả trên 31 bệnh nhân ung thư thanh quản giai đoạn III - IV tại bệnh viện K giai đoạn 2018 - 2021.Các bệnh nhân được hóa xạ trị đônng thời triệt căn. Mô tả một số đặc điểm lâm sàng, cận lâm sàng và đánh giá kểt quả điều trị.-Kết quá: Tuổi trung bình 58,6 $\pm 7,1$. Tỷ lệ nam/nữ là 30/1. Tỷ lệ nuốt vướng 41,9\%, khàn tiếng 41,9\%. Vị trí khối u ở thượng thanh môn chiếm $67,7 \%$. Có 18 $(58,1 \%)$ bệnh nhân giai đoạn III và $13(41,9 \%)$ bệnh nhân ở giai đoạn IVa. Có $77,4 \%$ bệnh nhân sử dụng phác đồ điều trị này là do từ chối phẫu thuật. Tỷ lệ đáp ứng toàn bộ sau hóa xa trị là $87 \%$, tỷ lệ đáp ứng 1 phân là $13 \%$, không có bênh nhân nào không đổi sau điều trị. Độc tính trên hệ huyết học là hạ bạch câuu độ II $(25,8 \%)$, hạ tiểu câu độ II $(19,4 \%)$. Độc tính

\footnotetext{
${ }^{1}$ Trường Đại học Y Hà Nội

${ }^{2}$ Bềnh viện $K$

Chịu trách nhiệm chính: Bùi Sơn Hải

Email: buisonhaibvk@gmail.com

Ngày nhận bài: 20.8.2021

Ngày phản biên khoa học: 13.10.2021

Ngày duyệt bài: 21.10 .2021
}

\section{Bùi Sơn Hải ${ }^{1}$, Ngô Thanh Tùng ${ }^{2}$}

viêm da độ II do xạ trị (38,7\%), viêm miệng độ III do xa trị $(45,2 \%)$. Kêt luận: Phác đồ cho tỷ lệ đáp ứng tổt, an toàn, độc tính chấp nhận được.

Tư khóa: Ung thư thanh quản, hóa xạ trị đồng thời, IMRT, giai đoạn III-IV

\section{SUMMARY}

\section{THE RESULTS OF CONCURRENT CHEMORADIOTHERAPY (IMRT) FOR LARYNX CANCER STAGE III - IV AT NATIONAL CANCER HOSPITAL}

Objective: Describe clinical characteristics and evaluate outcome of chemoradiotherapy in patients with stage III - IV larynx cancer at National Cancer Hospital. Material and Method: A descriptive crosssectional study performed on 31 patients with stage III - IV larynx cancer at National Cancer Hospital from 2018 to 2021. The patients received definitive concurrent chemoradiotherapy. Describe some clinical and para-clinical characteristics and evaluate treatment results. Results: The average age was 58.6 \pm 7.1 years [41-69]. The male/female ratio was 30/1. The rate of dysphagia was $41.9 \%$. The site of lesions at supraglottic accounted for $67.7 \%$. There were 18 $(58.1 \%)$ stage III patients and $13(41.9 \%)$ patients at stage IVa. There were $77.4 \%$ of the patients treated with this protocol because of refusal of surgery. The overall response rate after chemoradiation was $87 \%$, the partial response rate was $13 \%$. Toxicity grade II 
on the hematopoietic system includes leukopenia $(25.8 \%)$, and thrombocytopenia grade II (19.4\%). Radiation dermatitis grade II was $38,7 \%$, radiotioninduced stomatitis grade III was $45.2 \%$. Conclusion: The chemoradiotherapy regimen is an effective and safe regimen, toxicity were acceptable

Keywords: Larynx cancer, concurrent chemoradiotherapy, IMRT, III-IV stage

\section{I. ĐẶT VẤN ĐỀ}

Ung thư thanh quản là tổn thương ác tính xuất phát từ lớp biểu mô vảy của niêm mạc bao phủ thanh quản. Ung thư thanh quản chiếm khoảng $1 \%$ trong tổng số các loại ung thư. Theo GLOBOCAN 2018, ung thư thanh quản đứng thứ 23 với tỉ lẹ mắc chuẩn theo tuổi ở nam là 3.6/100.000 dân/ năm, ở nữ là $0.5 / 100.000$ dân/ năm. ${ }^{1}$ Ung thư thanh quản chiếm khoảng $1 \%$ trong tổng số các loại ung thư. . $^{1,2}$

Ung thư (UT) Thanh quản ít được chẩn đoán ở giai đoạn sớm do các triệu chứng khởi đâu thường âm thầm, các triệu chứng không rõ ràng nên bệnh nhân thường chủ quan. Phần lớn bệnh nhân nhập viện khi bệnh đã ở giai đoạn muộn (III, IV). Khi đó khối u lớn, xâm lấn rộng, hạch di căn lớn, phá vỡ vỏ, xâm lấn mạch máu hoặc di căn xa nên điều trị ít hiệu quả, tiên lượng xâu.

Trước đây, phẫu thuật là phương pháp cơ bản trong chiến lược điều trị ung thư thanh quản. Giai đoạn còn phẫu thuật được thường tiến hành cắt ha họng thanh quản toàn phần hoặc một phần cho kết quả tương đối khả quan. Tuy vây, bệnh nhân phải mất thanh quản và mang lố thở suốt đời, ảnh hưởng đến chất lượng cuộc sống. Hóa xạ đồng thời mang lại cơ hội bảo tồn thanh quản cao hơn khi so sánh với xạ trị đơn thuần hoăc hóa trị cảm ứng cùng với xạ trị dù độc tính cấp cao hơn nhưng không cải thiện sống thêm. Hóa chất nền tảng trong phác đồ hóa xạ trị đồng thời là Cisplatin. Điều trị bảo tồn bằng phương pháp không phẫu thuật cho ung thư thanh môn hoặc thượng thanh môn giai đoạn III/IV đã được đánh giá trong các thử nghiệm lâm sàng ngẫu nhiên so sánh hóa trị cảm ứng rồi xạ trị nếu đáp ứng, hóa xạ trị đồng thời và xạ trị đơn thuần.

Trên thế giới đã có nhiều nghiên cứu về điều trị hóa xạ đồng thời UT Thanh quản giai đoạn III-IV với kết quả khả quan. Bệnh viện $\mathrm{K}$ là cơ sở chuyên sâu, tuyến cuối trong điều trị ung bướu. Tuy vậy các nghiên cứu thường gộp chung ung thư hạ họng - thanh quản mà đến nay chưa có đề tài nào nghiên cứu đi sâu trong lĩnh vực này. Do vậy, để ghép thêm một phần nâng cao chất lượng về chẩn đoán cũng như điều trị UT Thanh quản và đánh giá kết quả điều trị trong thời gian qua chúng tôi tiến hành nghiên cứu đề tài: " Kết quả hóa xạ trị (IMRT) đồng thời ung thư thanh quản GĐ III/IV tại bệnh viện K" với 2 mục tiêu:

1. Nhận xét đặc điểm lâm sàng và cận lâm sàng của bệnh nhân ung thư thanh quản giai đoạn III-IV taii BV K từ 2018 - 2021

2. Đánh giá kết quả hóa xạ trị đồng thời ở nhóm bệnh nhân trên.

\section{II. ĐỐI TƯỢNG VÀ PHƯƠNG PHÁP NGHIÊN CỨU}

2.1 Đối tượng nghiên cứu. 31 bệnh nhân với chẩn đoán ung thư thanh quản GĐ III/IV, được điều trị hóa xạ trị đồng thời từ năm 2018 đến năm 2021.

\subsubsection{Tiêu chuẩn lựa chọn bệnh nhân}

- Từ 18-70 tuổi

- Chẩn đoán: ung thư thanh quản giai đoạn

III-IV, MO

- Bệnh ở giai đoạn còn mổ được

- BN từ chối mổ hoặc có bệnh nội khoa chống chỉ định mổ

- Chức năng gan thân và tủy xương bình thường

- Đồng ý phác đồ hóa xạ trị

\subsubsection{Tiêu chuấn loaì trư}

- Bênh nhân đã điều trị UT Thanh quản trước đó.

- Bểnh nhân chống chỉ định với điều trị hóa chất.

- Bệnh nhân bỏ điêuu trị ngoài lý do chuyên môn.

- Bệnh nhân có hai ung thư đồng thời

\section{Phương pháp nghiên cứu}

Thời gian nghiên cứu: Từ tháng 1 năm 2018 đến tháng 10 năm 2021

Địa điểm nghiên cứu: Bệnh viện $\mathrm{K}$

Thiết kế nghiên cứu: Phương pháp nghiên cứu mô tả cắt ngang.

Cỡ mẫu

- Chọn mẫu thuận tiện.

- Chọn tất các bệnh nhân đủ tiêu chuẩn trong thời gian nghiên cứu.

\section{KẾT QUẢ NGHIÊN CỨU}

Đặc điểm lâm sàng và cận lâm sàng của nhóm bệnh nhân nghiên cứu.

- Tuổi

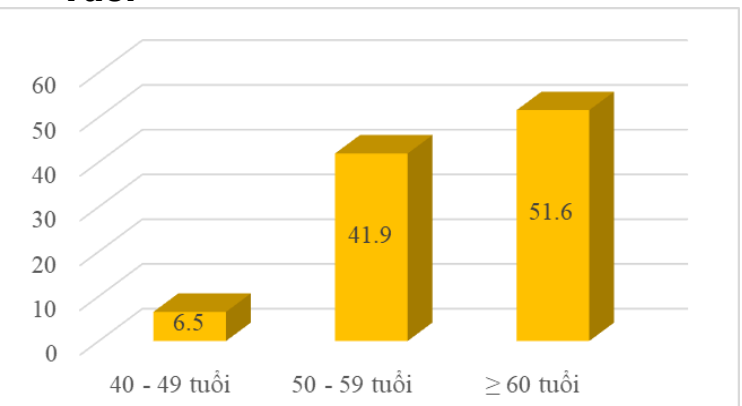

Biểu đồ 1: Phân bố bệnh nhân theo nhóm tuổi 
Nhận xét: Hơn một nửa $(51,1 \%)$ bệnh nhân trong nghiên cứu có độ tuổi từ 60 trở lên. Tuổi trung bình của BN là 58,6 \pm 7,1, [41-69].

- Giới

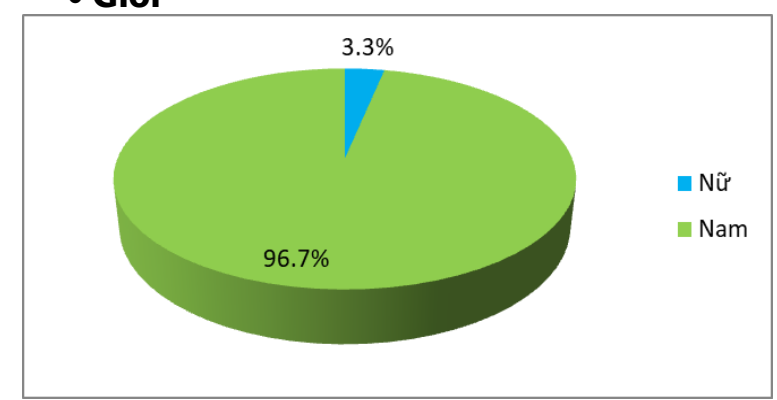

Biểu đồ 2: Phân bố bệnh nhân theo giới tính

Nhận xét: Tỷ số nam/ nữ là 30/1 trong đó nam chiếm $96,7 \%$

- Lý do vào viện

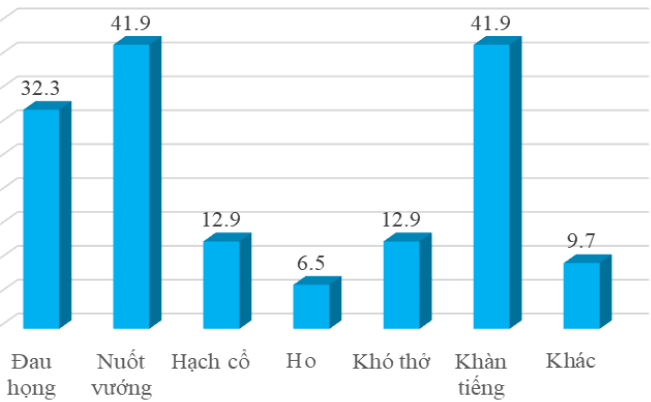

Biểu đồ 3: Lý do vào viện

Nhân xét: Đa số bênh nhân đến viên vì khàn tiếng $(41,9 \%)$, nuốt vướng $(41,9 \%)$ và đau họng $(32,3 \%)$.

- Giai đoạn bệnh

Bảng 1. Giai đoạn bênh trước điều trị

\begin{tabular}{|c|c|c|}
\hline Giai đoạn bệnh & Số BN & $\%$ \\
\hline III & 18 & 58,1 \\
\hline IVa & 13 & 41,9 \\
\hline
\end{tabular}

Các tác dụng phụ:

Bảng 2: Độc tính cấp trên hệ tạo huyêt

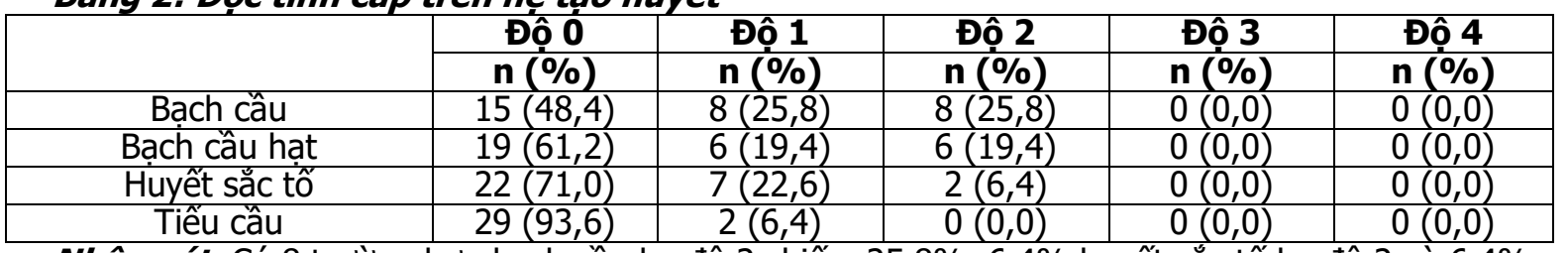

Nhận xét: Có 8 trường hợp bạch câu hạ độ 2 chiếm $25,8 \%$. 6,4\% huyết sắc tố hạ độ 2 và $6,4 \%$ tiểu cầu ha đô 1.

Bảng 3: Độc tính cấp trên gan thận

\begin{tabular}{|c|c|c|c|c|c|}
\hline & Độ 0 & Độ 1 & Độ 2 & Độ 3 & Độ 4 \\
\hline & $\mathbf{n ~ ( \% )}$ & $\mathbf{n}(\%)$ & $\mathbf{n}(\%)$ & $\mathbf{n}(\%)$ & $\mathbf{n}(\%)$ \\
\hline AST & $21(67,7)$ & $5(16,1)$ & $4(12,9)$ & $1(3,2)$ & $0(0,0)$ \\
\hline ALT & $21(67,7)$ & $5(16,1)$ & $4(12,9)$ & $1(3,2)$ & $0(0,0)$ \\
\hline Bilirubin & $29(93,5)$ & $2(6,5)$ & $0(0,0)$ & $0(0,0)$ & $0(0,0)$ \\
\hline
\end{tabular}

Nhận xét: Trong nghiên cứu của chúng tôi, tỉ lệ bểnh nhân đang ở giai đoạn III là $58,1 \%$ và giai đoan IVa là $41,9 \%$.

- Lý do không phẫu thuật của bệnh nhân:

\section{Biểu đồ 4: Lý do không phẫu thuật của bênh nhân}

Nhận xét: Phần lớn $(77,4 \%)$ bệnh nhân điều sử dụng phác đồ điều trị này là do bệnh nhân từ chối phẩu thuât. Chỉ có $22,6 \%$ bệnh nhân không có chỉ định phẫu thuật..

\section{Kết quả điêu trị.}

Kêt quả điều trị sau hóa xạ đồng thời

\section{Biểu đồ 5: Đánh giá đáp ứng sau hóa xạ đồng thời}

Nhận xét: Trong nghiên cứu của chúng tôi, sau hóa xạ trị đồng thời, tỉ lệ bệnh nhân đáp ứng hoàn toàn sau điều tri là $87 \%$, chỉ có $13 \%$ bệnh nhân đáp ứng 1 phần sau điều trị, không có bệnh nhân nào không thay đổi so với trước điều trị. 


\begin{tabular}{|c|c|c|c|c|c|}
\hline Ure & $28(90,3)$ & $3(9,7)$ & $0(0,0)$ & $0(0,0)$ & $0(0,0)$ \\
\hline Creatinine & $26(83,9)$ & $4(12,9)$ & $1(3,2)$ & $0(0,0)$ & $0(0,0)$ \\
\hline
\end{tabular}

Nhận xét: Có 1 trường hợp bị ảnh hưởng bởi quá trình hóa xạ trị làm men gan ALT tăng độ 3 và 1 trường hợp AST tăng độ 3.

Bảng 4: Biến chứng toàn thân, hệ tiêu hóa, da và niêm mạc

\begin{tabular}{|c|c|c|c|c|c|}
\hline & Độ 0 & Độ 1 & Độ 2 & Độ 3 & Độ 4 \\
\cline { 2 - 5 } & $\mathbf{n ~ ( \% )}$ & $\mathbf{n} \mathbf{( \% )}$ & $\mathbf{n} \mathbf{( \% )}$ & $\mathbf{n ~ ( \% )}$ & $\mathbf{n}(\%)$ \\
\hline Mệt mỏi & $0(0,0)$ & $23(74,2)$ & $8(25,8)$ & $0(0,0)$ & $0(0,0)$ \\
\hline Nôn & $18(58,1)$ & $13(41,9)$ & $0(0,0)$ & $0(0,0)$ & $0(0,0)$ \\
\hline Viêm da & $0(0,0)$ & $19(61,3)$ & $12(38,7)$ & $0(0,0)$ & $0(0,0)$ \\
\hline Viêm miệng & $0(0,0)$ & $3(9,6)$ & $14(45,2)$ & $14(45,2)$ & $0(0,0)$ \\
\hline Khô miệng & $1(3,2)$ & $20(64,5)$ & $10(32,3)$ & $0(0,0)$ & $0(0,0)$ \\
\hline Khó nuốt & $2(6,4)$ & $12(38,7)$ & $15(48,5)$ & $2(6,4)$ & $0(0,0)$ \\
\hline
\end{tabular}

Nhận xét: Hâuu hết bệnh nhân đêu bi ảnh hưởng của tia xạ gây mệt mỏi trong đó mệt mỏi ảnh hưởng đến sinh hoat chiếm tỷ lệ 25,8\%. Số bênh nhân có tình trạng nồn do kích thích niêm mạc miệng chiếm tỷ lệ $41,9 \%$. Vì vậy việc chăm sóc điều dưỡng cho bệnh nhân trong quá trình xạ trị là hết sức cần thiết.

\section{BÀN LUẬN}

Một số đặc điểm lâm sàng, cận lâm sàng. Tuổi mắc bệnh trong nghiên cứu của chúng tôi nằm trong khoảng từ $41-69$ tuổi. Tuổi mắc bênh trung bình là $58,6 \pm 7,1$ tuổi. Theo kết quả này thì tuổi trung bình của bệnh nhân trong nghiên cứu của chúng tôi cao hơn so với nghiên cứu của tác giả Đàm Trọng Nghĩa với tuổi trung bình là $53,2 \pm 7,3$ tuổi. ${ }^{3}$

Trong nghiên cứu của chúng tôi bênh gặp chủ yếu ở nam giới, chiếm tỷ lệ $96,7 \%$, tỳ lệ nam/ nữ là 30/1. Nhiều nghiên cứu trước đây cũng cho thấy cung thư thanh quản gặp chủ yếu là nam giới, nữ giới chiếm tỉ lệ rất ít như: nghiên cứu của Pham Tuấn Cảnh với tỉ lệ nam giới là $97 \%{ }^{4}$, nghiên cứu của Marshall R.P. và cộng sự với tî lệ nam giới là $84 \%^{5}$ hay nghiên cứu của Arlene Á.F và cộng sự về Hóa xạ trị đồng thời để bảo tồn trong ung thư thanh quản giai đoạn muộn cũng có tỉ lệ nam giới là $77,6 \%{ }^{6}$

Lý do vào viện. Nghiên cứu của chúng tôi cho thây đa số bệnh nhân đến viện vì khàn tiếng $(41,9 \%)$, nuốt vướng $(41,9 \%)$ và đau họng $(32,3 \%)$. Các triệu chứng này cũng gặp nhiêuu trong nghiên cứu của Phạm Tuấn Cảnh năm 2011 với các triệu chứng khàn tiếng $(100 \%)$, rối loạn nuốt $(27 \%)$, khó thở thanh quản $(20 \%)^{4}$. Nghiên cứu của Thái Đình Hiếu cũng cho thấy các triệu chứng thường gặp là rối loạn nuốt 93/101(92,1\%), nổi hạch cổ 74/101 (73,3\%), khàn tiếng $21 / 101(20,8 \%)^{7}$. Do bênh nhân trong nghiên cứu của chúng tôi phát hiện bệnh ở giai đoạn muộn nên đã có các triệu chứng do chèn ép khối u như nuốt vướng, khó thở, hạch cổ,..

Giai đoạn bệnh: Trong nghiên cứu của chúng tôi chỉ lấy những bệnh nhân ung thư thanh quản ở giai đoạn III hoăc IVa với tỉ lệ bệnh nhân đang ở giai đoạn III là $58,1 \%$ và giai đoạn IVa là $41,9 \%$. Tỉ lệ này thấp hơn so với nghiên cứu của Thái Đình Hiếu và cộng sự về nghiên cứu đặc điểm lâm sàng, cân lâm sàng ung thư hạ họng - thanh quản giai đoạn III,IVA$B$ tại bệnh viện Ung bướu Nghệ An năm 2020 với tỉ lệ bệnh nhân ở giai đoạn IV $(69,3 \%)^{7}$. Và nghiên cứu của Đàm Trong Nghĩa với tỉ lệ bênh nhân ở giai đoạn III (4,9\%) và IV (IVa là $56,1 \%$, IVb là $39 \%)^{3}$.

Từ chối phẫu thuật: Hiện tại, có đủ bằng chứng để kết luận rằng điều trị ung thư thanh quản tiến triển T4 trong thực hành lâm sàng nên xem xét cắt thanh quản toàn phần vì sống thêm tốt hơn hóa xạ đồng thời, tuy nhiên trong nghiên cứu của chúng tôi, tỉ lệ từ chối phẫu thuật khá cao $77,4 \%$. Điều này có thể lý giải là do khi phẫu thuật bệnh nhân phải mất thanh quản và mang Iỗ thở suốt đời, ảnh hưởng đến chất lượng cuộc sống của bệnh nhân. Trong nghiên cứu của Đàm Trọng Nghĩa, tỉ lê gia đình từ chối phẫu thuật chỉ chiếm $7,3 \%$, thẩp hơn nhiều so với nghiên cứu của chúng tôi. ${ }^{3}$ Rõ ràng là quyết định điều trị chính có thể phụ thuộc vào mong muốn của bênh nhân, giai đơạn u, kinh nghiệm của nhóm điều trị, khả năng theo dõi sau điều trị, sự kỳ vọng về lâu dài chức năng nói và nuốt.

Kết quả điêu trị. Trong nghiên cứu của chúng tôi, sau hóa xạ trị đồng thời, tỉ lệ bệnh nhân đáp ứng hoàn toàn sau điêu trị là $87 \%$, chì có $13 \%$ bệnh nhân đáp ứng 1 phần sau điều trị, không có bệnh nhân nào không thay đổi so với trước điều trị. Tỉ lệ đáp ứng hoàn toàn với điêu tri trong nghiên cứu này cao hơn so với nghiên cứu của Đàm Trọng Nghĩa $(29,3 \%)$ và nghiên cứu của Ngô Thanh Tùng trên bệnh nhân ung 
thư hạ họng thanh quản giai đoạn III, IV bằng phác đồ hóa xạ trị đồng thời với cisplatin năm $2011(56,7 \%))^{3,8}$

\section{Tác dụng phụ}

- Độc tính trên huyết học, gan, thận. Trong quá trình điều trị đến khi kết thúc hóa xạ trị đồng thời, có 1 trường hợp bị ảnh hưởng bởi quá trình hóa xạ trị làm men gan ALT tăng độ 3 và 1 trương hợp AST tăng độ 3 . Trên hệ huyết học, có 8 trường hợp bạch cầu hạ độ 2 chiếm $25,8 \% .6,4 \%$ huyết sắc tố hạ độ 2 và $6,4 \%$ tiểu câu ha độ 1 .

\section{- Tác dụng phụ của xạ trị}

Viêm miệng do tia xạ. Kết quả trong nghiên cứu của chúng tôi, tỷ lệ bệnh nhân bị viêm miệng trong quá trình điểu trị là $100 \%$, trong đó có $9,6 \%$ gặp ở độ $1,45,2 \%$ độ 2 và $45,2 \%$ bị viêm miệng độ 3 . Tî lệ viêm viêm miệng độ 3 ở nghiên cứu này cao hơn so với nghiên cứu của Vũ Việt Anh (14,3\% độ 3, 71,4\% độ $2,14,3 \%$ độ 1). ${ }^{9}$

Tác dụng phụ trên da. Trong nghiên cứu của chúng tôi, các tổn thương da do tia xa gặp tỷ lệ 38,7\% bệnh nhân bị độc tính trên da cấp độ 2 . Kết quả này thấp hơn so với nghiên cứu của Vũ Việt Anh là $66,7 \% .{ }^{9}$

\section{KẾT LUẬN}

Đối với bệnh nhân UT Thanh quản giai đoạn III - IV có chỉ định phẫu thuật mà từ chối mổ hoặc có bệnh nội khoa chống chỉ định mổ được điều trị hóa xạ trị đồng thời (IMRT) cho tỷ lệ đáp ứng toàn bộ sau hóa xạ trị là $87 \%$, tỷ lệ đáp ứng 1 phần là $13 \%$, không có bệnh nhân nào không đổi sau điều trị. Các độc tính ở mức chấp nhận được trên hệ huyết học là hạ bạch câu độ II
(25,8\%), hạ tiểu cầu độ II $(19,4 \%)$, viêm da độ II do xạ trị $(38,7 \%)$, viểm miệng độ III do xạ trị $(45,2 \%)$

\section{TÀI LIÊUU THAM KHẢO}

1. Freddie B., Jacques F., Isabelle S., Rebecca L.S., Lindsey A.T., Ahmedin J. Global cancer statistics 2018: GLOBOCAN estimates of incidence and mortality worldwide for 36 cancers in 185 countries. CA Cancer J Clin. 2018;68(6):394-424.

2. C R Popescu., S V G Bertesteanu., D Mirea., Raluca G., Diana I., B Popescu. The epidemiology of hypopharynx and cervical esophagus cancer. J Med Life. 2010;3(4):396-401.

3. Đàm Trong Nghĩa. Nghiên cứu ứng dụng hóa trì trước phối hợp hóa xạ trị đồng thời ung thư hạ hong thanh quản giai đoan III, IV(MO): Luận án Tiến sĩ Y hoc, Trướng Đại hooc Y Hà Nội; 2018.

4. Phạm Tuẩn Cảnh, Nguyễn Hoàng Huy. Nghiên cứu đặc điểm lâm sàng ung thư thanh quản tại Bênh viện Tai Mũi Họng trung ương. $Y$ học thực hà̀nh. 2011;768(6):69-71.

5. Marshall R. P., Diane M.H., Cesar R.B., et al. Cisplatin and Fluorouracil Alone or with Docetaxel in Head and Neck Cancer. N Engl J Med. 2007;357(17):1705-1715.

6. Arlene A.F., Helmuth G., Moshe M., et al. Concurrent Chemotherapy and Radiotherapy for Organ Preservation in Advanced Laryngeal Cancer. N Engl J Med. 2003;27(349):22.

7. Thái Đình Hiếu, Nguyễn Tiến Quang. Nghiên cứu đặc điểm lâm sàng, cận lâm sàng ung thư ha hong - thanh quản giai đoạn IIIIIVA_B tại bênh viền Ung bướu Nghê An năm 2020. Tạp chí Y hộc Việt Nam. 2021;501(1):199-203.

8. Từng NT. Nghiên cứu một số đặc điểm lâm sàng, cận lâm sàng và kết quả hoá - xạ trị gia tốc đông thời ung thư ha họng -thanh quản giai đoạn III IVB không mổ được tại Bênh viện K 2011: Luận án Tiến sỹ Y học Trường Đại học Y Hà Nội; 2011.

9. Anh VV. Đánh giá kêt quả điêu trị bố trợ sau mổ ung thư lưỡi tại bệnh viện $K$ : Luận văn Thạc sĩ Y học, Trường đại học Y Hà Nội; 2015.

\title{
SỰ HÀI LÒNG VỀ DỊCH VỤ GIÁO DỤC CỦA SINH VIÊN HÊ BÁC SĨ NĂM THỨ 4 ĐẾN NĂM THỨ 6 TRƯỜ'NG ĐẠI HỌC Y HÀ NộI
}

\author{
Hoàng Việt Hưng ${ }^{1}$, Vũ Thu Hoài ${ }^{1}$, Phạm Tùng Sơn ${ }^{1}$,
} Nguyễn Thái Bình ${ }^{2}$, Vũ Minh Tuấn ${ }^{2}$

\section{TÓM TẮT.}

Mục tiêu: Nghiên cứu nhằm tìm hiểu sự hài lòng về dịch vụ giáo dục và phân tích một số yếu tố liên

\author{
${ }^{1}$ Trường Đại học Y Hà Nội \\ 2Viện Đào tạo YHDP \& YTCC, Trường Đại học Y Hà Nội \\ Chịu trách nhiệm chính: Vũ Minh Tuấn \\ Email: vuminhtuan@hmu.edu.vn \\ Ngày nhận bài: 17.8.2021 \\ Ngày phản biện khoa học: 11.10.2021 \\ Ngày duyệt bải: 22.10.2021
}

quan đến sự hài lòng của sinh viên hệ bác sĩ từ năm thứ 4 đến năm thứ 6 trường Đại học $Y$ Hà Nội. Phương pháp: Nghiên cứu mô tả cắt ngang, khảo sát trên 712 đối tượng theo bộ câu hỏi sẵn có của Bộ GD\&DT. Kết quả: $67,4 \%$ sinh viên đánh giá "Hài lòng" hoăc "Rất hài lòng" về chất lượng dịch vụ giáo dục Nhà trường. Phân tích mô hình hổi quy Logistic đa biến nhận thấy có mối liên quan giữa giới tính [OR = 1,4; CI: $1,02-1,93]$, dân tộc [OR = 2,27; CI: 1,04 $4,97]$, năm học [OR $=0,61 ; \mathrm{CI}: 0,42-0,89]$ và nơi ở hiện tại của sinh $[\mathrm{OR}=0,58 ; \mathrm{CI}: 0,36-0,95]$ với mức độ hài lìng chung về chất lượng dịch vụ giáo dục Nhà trường. 